DOI: $\underline{10.20472 / B M .2021 .9 .2 .001 ~}$

\title{
AN EMPIRICAL STUDY ON INTER-ORGANIZATIONAL NETWORK STRUCTURES FOR AUTOMATED VEHICLES
}

\section{FUMIHIKO ISADA}

\begin{abstract}
:
This study aimed to examine empirically whether rapid changes in the technological environment affect inter-organizational relationships. In the automotive industry, the advantage of cohesive and vertically integrated inter-organizational relationships has been pointed out conventionally. The development of automated driving in the automotive industry, which is the subject of this thesis, is eliciting significant changes in the traditional automotive products and industry structure - changes generally associated with the automotive product structure moving closer to IT products. And, sharply conflicting views are found in previous studies as to whether this traditional inter-organizational network will change. As a methodology, I aimed to clarify empirically what kind of network structure of inter-organizational relations firms is growing with changes in industrial structure by creating a database of actual firm behavior. The database was analyzed using the social network analysis method, and the characteristics of growing firms' organizational network structure were extracted. The results from an analysis of a large number of databases indicated that the technological change from automated driving may have prompted a change in inter-organizational relations toward a horizontal division of labor in the automobile industry in which so-called platform leader companies would emerge.
\end{abstract}

\section{Keywords:}

network formation, partnership, technological change, open innovation ecosystem, vertically integrated

JEL Classification: M11, 032, M19

\section{Authors:}

FUMIHIKO ISADA, Kansai University, Japan, Email: isada@kansai-u.ac.jp

\section{Citation:}

FUMIHIKO ISADA (2021). An empirical study on inter-organizational network structures for automated vehicles. International Journal of Business and Management, Vol. IX(2), pp. 1-18., 10.20472/BM.2021.9.2.001 


\section{Introduction}

This paper's purpose is to conduct an exploratory empirical study on the structural impact from inter-organizational networks surrounding firms on their growth potential in the automotive industry, which is currently undergoing rapid changes in its industrial structure.

The network structure of firms' inter-organizational relationships varies, depending on the industry characteristics and product structure to which the firms belong. Technological differences affect industry characteristics and product structures, such as component composition, and the optimal inter-organizational network also is likely to differ in each case. The traditional automobile industry has functioned under a network structure of closed and strong inter-organizational relationships with a specific group of firms. As for consumers' choice of passenger cars, how each consumer values passenger cars is influenced greatly by each car's individuality, e.g., different concepts and brand values. Therefore, to realize each car's individuality, different special products are developed for each car's main parts and materials. A car comprises tens of thousands of parts and materials, and integrated coordination between all of these is important in realizing the car's concept and design. For this reason, each car manufacturer works closely with specific component and material manufacturers in the development, design, and manufacture of its products. To exchange important technical, development, and design information with partners in a flexible manner and prevent leakage of such information to non-partners, each automobile manufacturer has strengthened its human and capital relationships with a limited number of specific partners, forming a strong inter-organizational network over the long term. The result has been a vertically integrated, closed, and cohesive ecosystem in the automotive industry, dominated by complete vehicle manufacturers.

However, the IT industry, for example, has opted for a relatively open, ad hoc, and weak network structure of inter-organizational relationships. More specifically, computers and the Internet have standardized interfaces that are available for free or for a fee, and have become increasingly modular (Ulrich, 1995) in their components. This has made it possible for a wide variety of players to enter the market and has encouraged the creation of countless venture companies specializing in particular technologies. This makes it easier to improve product performance, add new functions, reduce costs, and rapidly increase cost-effectiveness for consumers. The IT industry has seen the emergence of so-called platformers (or platform leaders) that specialize in a particular function, expand their inter-organizational networks to include a variety of firms, and become dominant in certain areas. In the IT industry, platformers have created an open and horizontal division-of-labor ecosystem.

And now, the development of automated driving in the automotive industry, which is the subject of this thesis, is eliciting significant changes in the traditional automotive products and industry structure - changes generally associated with the automotive product structure moving closer to IT products. Such dramatic technological changes in the industry include those under the umbrella term Connected, Autonomous, Shared, and Electric vehicles (CASE). The term was unveiled at the Paris Motor Show 2016, coined by Mercedes-Benz as part of its medium- and long-term strategy, but is used widely in the automotive industry today. For example, Connected refers to the car's transformation into an information and communication device. Automated driving also entails the car's transformation into an IT product, and sharing reduces the consumer value added by owning a car. If all cars become like shared buses and taxis, consumer values, such as a car's design and the status of owning a luxury car, will become meaningless. As a 
result, a car's value will shift from hardware to services, and the industry's structure will change. In addition, electric vehicles will lead to a simplification of the car's structure, as well as a significant reduction in the number of components in it, which will reduce the need for integrated coordination between components and could lead to a much smaller number of component manufacturers. As a result, existing car manufacturers and component suppliers are undergoing a desperate change in strategy to survive.

Under such changes in the technological environment, the group of companies related to the automobile industry is changing in various ways. And the aspect of the change seems to be different from country to country. In the United States, there are a mixture of major existing automobile manufacturers and parts manufacturers, as well as IT companies trying to enter the automobile industry. Existing companies are currently actively working on new technologies and services while extending the lives of existing businesses. Companies in various industries, including the IT industry, have entered the automobile and related industries, and are actively engaged in technological development and the creation of new business models. Especially in the area of autonomous driving, giant IT companies such as Google and Apple have entered the market, aiming to become a new platformer based on their excellent technological base.

In Europe and Japan, in the area of automated vehicles, mainly large existing car manufacturers and parts suppliers are actively working on new technologies and services, while trying to extend the life of their existing businesses. However, Japanese companies have so far lagged behind their foreign counterparts in terms of changes to automated vehicles. Some of the reasons for Japan's delay include strict legal restrictions on self-driving cars and the fact that the main source of competitive advantage has been the strong relationships between companies in existing businesses. On the other hand, in China, unlike in Europe, the US and Japan, there were no internationally competitive firms in the existing automotive industry. However, in new technology areas such as electric vehicles, a number of Chinese firms are rapidly realising innovations and emerging as major global players.

In this study, we aimed to clarify empirically what kind of network structure of inter-organizational relations firms is growing with changes in industrial structure by creating a database of actual firm behavior. However, changes in each CASE vehicle's industrial structure are expected to be different; therefore, it is necessary to separate the changes in each of the four areas and analyze them separately. For example, Fujimoto (2020), from the perspective of product architecture, categorized ICT-related companies, whose industrial structure is open and modular, as the "sky" and the existing automobile industry, whose architecture mainly is closed and integral, as the "ground": "The Connected is likely to be led by Google, Apple, etc., in the 'sky.' Electric vehicles, on the other hand, will be led by automotive and power electronics companies on the 'ground,' " because they understand the laws of physics. The automated driving and car-sharing sector will entail a complex interplay of competition and collaboration between ICT companies with network power and car manufacturers with automotive asset knowledge. In this study's analysis, among the four CASE areas, the focus is on self-driving cars, which are difficult to understand in the mainstream due to the mixture of "sky" and "ground."

In this study, we attempted to analyze these changes quantitatively by using the theory and method of social network analysis, although there are various possible research methods such as individual case studies. Social network theory applies various theories on the properties of complex networks in the natural sciences (e.g., small-world, scale-free, cluster property, etc.) to social relations. By considering people and organisations as nodes and analysing the structure of 
the networks in which they are connected to other nodes, it is possible to identify the effects of embedded relationships between people and organisations on their thinking and behaviour. The methods of social network theory allow us to calculate various quantitative indicators to evaluate the network structure. As for the data used in the analysis, a database was constructed by extracting press releases and English-language newspaper articles to include as much information as possible from all over the world, including the latest information. The database then was analyzed using the social network analysis method, and the characteristics of growing firms' organizational network structure were extracted.

\section{Previous studies on inter-organizational relations}

Prior to the analysis, we review some previous studies on the relationship between industryspecific characteristics and inter-organizational relations.

\subsection{The Inter-Organizational Network in the Automotive Industry}

As mentioned above, the inter-organizational network between a manufacturer of finished vehicles and a manufacturer of parts and materials in the traditional automotive industry was closed and cohesive. The keiretsu system within Japanese companies is a typical example of such a vertically integrated inter-organizational network, with the finished vehicle manufacturer at the top of the pyramid. Sharply conflicting views are found in previous studies as to whether this traditional inter-organizational network will change in the wake of CASE. In Japan, the automobile industry is one of the most competitive industries in the world, with a wide scope, as a large part of the nation's employment depends on the automobile industry. Inter-organizational networks, such as the Japanese keiretsu system, are recognized as an important source of competitive advantage for Japanese automakers, and there has been much discussion in the academic community about changes in inter-organizational networks over the years.

For example, Murasawa (2010) positions electric vehicles as a modular architecture and predicts a decline in complete car manufacturers. For example, he recognizes electric vehicles as a product that can be developed and manufactured by combining electric motors and on-board batteries produced by several component manufacturers. This makes it possible for small-scale businesses, such as local auto repair and electronics shops, to develop, produce, and sell electric vehicles by combining mutually interchangeable parts, and finished vehicle manufacturers, who traditionally have controlled a large share of the car market, will decline in the long run.

In contrast, Saeki (2011) states that electric vehicles' overall product architecture has the characteristics of the integral type (Ulrich, 1995). Saeki's argument is that electric vehicles are products that require not only a combination of interchangeable parts, but also complex software used for electronic control, requiring complex coordination in software development. However, even electric vehicles require a high level of coordination between automakers and suppliers, including software development, so complete vehicle manufacturers will remain competitive and reign supreme in the electric vehicle market.

\subsection{Network Size, Openness, and Firm Growth}

The above discussion is related to the issue of whether innovations are more likely to be produced by integrated or decentralized inter-organizational networks. According to a series of discussions on open innovation since Chesbrough (2003), it is assumed that the breadth of partners increases opportunities for new combinations of knowledge and promotes innovation. 
Adapting the dynamic capability argument of Teece, Pisano, \& Shuen (1997), when the technology is immature and uncertain, it is more desirable to select more types of technologies competitively, both internally and externally, by expanding the inter-organizational network. Also, by collaborating with various partners, it is easier to disseminate their technical specifications and achieve standard status.

\subsection{Platformisation and Firm Growth}

Several previous studies have argued that platform-type products and services, or platformers that provide them, promote technological innovation in interorganizational networks. The theoretical premise for the formation of platforms is that the structure of a product or industry is becoming modular (Ulrich, 1995). For example, in the case of computers and IT products, modularity facilitates the division of labor and allows individual firms to concentrate their management resources on their own specialized business areas, thereby promoting efficient research and development. New entrants are encouraged to enter the market, and new products and services are created successively through the heavy production and high failure rate of innovation by many firms, with cost performance enhanced through competition.

The foundation of such horizontal division-of-labor-type innovation is the platform. One of the earliest and best studies on platforms is a platform leadership study by Gawer and Cusumano (2002), which analyzed Intel's strategy for personal computers, along with follow-up studies. They defined a platform as a product or service that serves as the basis on which multiple complementary firms can make products or provide services. Regarding the relationship between platforms and innovation, Gawer and Cusumano (2014) defined an industrial platform as the foundation on which more firms can build complementary innovations of a particular product, related service, or component technology. Industry platforms tend to accelerate the innovation of complementary products and services. The greater the complementary innovation, the greater the value created for the platform and its users through network effects, creating a cumulative advantage for existing platforms. These complementary elements become barriers to entry, as it becomes more difficult for rivals and new entrants to remove them. However, Gawer and Cusumano (2008) highlighted the complex trade-off between "open" and "closed" innovation, i.e., they suggested that while open interfaces increase complementors' incentives to innovate and promote the platform's growth, they also make it more difficult to internalize and maintain the profit source.

Also, according to lansiti and Levien (2004), in business ecosystems, it is important to increase the innovation of complementary niche companies, rather than allowing only platform companies to grow and monopolize profits, in order to promote healthy growth of the entire ecosystem. Niche firms with products and technologies that are difficult to imitate are indispensable to platform firms, and niche firms that are sought-after by many platform firms also can grow and become more profitable. Furthermore, complementary firms' ability to connect to a platform allows the complementary innovator not only to create complementary innovations, but also to access the platform's customers directly or indirectly, thereby facilitating firm growth (Ceccagnoli, Forman, Huang, \& Wu, 2012; Cennamo and Santaló, 2013).

\subsection{Integrated Networks and Firm Growth}

However, many previous studies have explained integrated inter-organizational networks' usefulness, especially when the entire industry structure undergoes an innovative transformation. 
For example, in extant research on organizational learning, based on a series of studies on the search for and evolution of knowledge, starting with March (1991), if a company disperses its limited research and development (R\&D) resources and becomes more active in collaborating with outside parties, it is likely to lead to a decline in its own R\&D capacity. In addition, according to a series of studies on absorptive capacity since Cohen and Levinthal (1990), in research on organizational capacity, if the company's own R\&D capacity declines, its ability to understand and utilize external knowledge also may decline. In addition, even if the company diversifies its partners, the probability of success is likely to be low if the company forms an alliance with a partner that diverges significantly from its own R\&D content (Lane and Lubatkin, 1998).

According to Chesbrough and Kusunoki (2001), integral architecture is used mainly during an industry's early stage, during which integral organizational strategies become important because of the relative complexity of problem solving for innovation. While individual modules can respond autonomously to changes that can be solved within the module, it is difficult to respond to radical changes that span modules and change interface rules. Firms with a modular organizational structure are more likely to fail to lead or follow innovative technological change because they do not have a broad knowledge of the entire product. This phenomenon is known as the modularity trap.

Wessel, Levie, \& Siegel (2016) provided a case study of electric vehicles and pointed out the importance of strengthening interdependence in business ecosystems when innovative technological evolution occurs. During a new product's early stages, the inventor is not always clear about the interdependent relationships within the innovation's various components. For example, the first automobile manufacturers had to control research, design, and manufacturing tightly, considering that a change made to one part of the car often meant a change to the whole car. Therefore, product development required a network of interdependent partners. The more dramatic the technological innovation, the stronger the interdependence can be. In the current design and development of autonomous electric vehicles, interdependence close to a fully vertically integrated model is again necessary. Tesla's vehicles maintain the most interdependent architecture in the market, as the firm is trying to internalize every component of its vehicles and bring them under its control, including the hardware, the software that manages the complex electrical systems, and the algorithms and sensors that enable the automated driving functions. And the scope of its tight control extends even further, as it owns its distribution channels, service network, and charging network. This integrated model allows the company, along with its fastcharging batteries, to meet all the challenges involved in producing autonomous and long-range electric vehicles.

\section{Analysis Method and Research Hypotheses}

Next, we describe the method of social network analysis, which is the method for analyzing interorganizational relations in this study, and the hypotheses based on it.

There are two main types of networks that can be analysed in social network theory: socio centric networks and ego centric networks. The former, socio centric network, takes the whole network as the object of analysis. For example, it represents the overall characteristics of all the relationships of the world's car manufacturers and their partners. The ego centric network, on the other hand, is a self-centred network structure. Organizations are connected to each other in a broad network structure, but each organization is connected to the surrounding organizations in different ways. The main interest of ego centric network research is the difference in 
organizational performance due to the network structure around the organization. The subject of this study is the ego centric network in individual organizations.

One of the most prominent studies in social network analysis examined the weak-ties hypothesis proposed by Granovetter (1973), which empirically demonstrated the strength of weak ties. According to Granovetter (2005), interpersonal ties generally come in three varieties: strong, weak, or absent. The weak-ties hypothesis can be related to the management of innovation, in which a weak, but wide, network can promote innovation better than a strong, but narrow, network. In other words, in promoting innovation, it is necessary to search for knowledge that overcomes the limited rationality of people and organizations, and weak-but-wide networks are useful, as they allow for various forms of information to flow quickly and efficiently from a distance. However, a strong-but-narrow network tends to circulate only similar information, which makes it difficult for innovation to emerge, thereby preventing the organization from growing and improving its performance. This advantage of a wide network can be related to openness and open innovation in the aforementioned previous studies on inter-organizational relations.

With the change to self-driving cars, companies in the automotive industry need to work on various new technological elements that have not been covered in the past. For example, an enormous amount of work had to be done in the accumulation and analysis of big data for automated driving, the development of roads and satellites for location information, and communication with other vehicles. For this purpose, it is necessary to develop information and communication technologies, artificial intelligence, and other technologies that go beyond the boundaries of conventional automobiles. Furthermore, the change to self-driving cars, together with the changes in sharing and connectivity, will change the form of ownership and use for car users, as well as force companies to change their profit models. Rather than increase individual automobiles' profit margin and sales volume, companies will be required to shift to new revenue models, such as services and solutions related to transportation. To achieve this, automotiverelated companies are required to work together with not only the automobile industry, but also various companies, such as railroad and real estate companies, to develop the entire transportation system and the whole city. As described above, with the progress of automated vehicles, the issues targeted by the automobile industry, including automobile manufacturers, will become very broad, and it is assumed that the wider the inter-organizational network, the more the companies will grow. From the above assumptions, the following hypothesis is proposed:

Hypothesis 1: In the automated-vehicle industry, the more extensive the inter-organisational network, the greater the growth.

In addition, in social network analysis, it has been shown that not only the number of connections, but also the way in which an organisation is connected to the networks around it affects its behaviour and performance. For example, the study of ego-centric network structures focuses on the question of triadic closure, i.e. whether the nodes to which the ego node is directly connected are also connected to each other. When there is no direct connection between those who are connected to the actor (ego), a structural hole is said to exist between them (Burt, 1992). On the other hand, if two people who are connected to the actor (the ego) are themselves connected, the three people (the triad) are described as closed. The high network density of the ego represents the degree to which the ego network triad is closed (Phelps et al., 2012).

Burt (2004) classifies ties into Bridging Ties and Cohesive Ties, and states that Bridging Ties, which can be widely deployed even with weak connections, are effective in searching for information. Bridging Ties are defined as ties that connect separated individuals and groups. Its 
structural features include many bridge ties and a wide range of connectivity; these can be analysed by indexes such as the number of intervening ties and structural holes. Bridging Ties' strength lies in the widespread dissemination of new, formal, and heterogeneous knowledge, and it is easily linked to radical innovation.

Such a mediated network structure can be associated with platform leadership and ecosystems in the aforementioned previous studies on inter-organizational relations. Since platform leaders connect various firms, they are likely to be the nodes that mediate many nodes in the network structure. Moreover, if the nodes of the platform leader are highly mediating, then the complementary firms of the platform leader are likely to be nodes that are connected to highly mediating nodes.

The change to self-driving cars may bring automobiles' product structure closer to the modularity of computers. In such a horizontal division-of-labor industrial structure, the ecosystem's core firms are platformers, i.e., platform leaders (Gawer and Cusumano, 2002). Platform leaders can grow by expanding the entire ecosystem through collaborations with companies that supply complementary products and services around their own products and technical standards. Therefore, an important business strategy is to divide the company and its partners' business domains appropriately, increase the number of complementary companies as much as possible while aiming for coexistence and co-prosperity, and position the company's products and technologies as being dominant in the industry. For example, platform companies in the IT industry are expanding horizontally by creating new collaborative relationships with a large number of external companies beyond existing corporate affiliations and industries. With the shift to self-driving cars, the automotive industry is also undergoing restructuring, and it is assumed that each company is working to become a platformer company.

In addition, as the network structure among organizations becomes platform-based, companies that complement platform companies also are expected to grow, along with the entire ecosystem's growth. In particular, it is assumed that complementary firms that have rare products or technologies, and that collaborate with many platform firms, have high bargaining power in inter-organizational relationships and are growing. From the above assumptions, the following two hypotheses are proposed:

Hypothesis 2a: In the automated-vehicle industry, the greater the degree of mediation in the inter-organizational network, the greater the growth.

Hypothesis 2b: In the automated-vehicle industry, the greater the structural holes in the interorganizational network, the more the industry is growing.

Hypothesis 2c: In the automated-vehicle industry, the greater the degree of connection with a company with high mediation, the more it grows.

In addition to the aforementioned network size and mediation of a particular node, we can also focus on the mutual cohesion and proximity of connected nodes in social network analysis. For example, the density of a network is the degree to which other nodes connected to a node are also connected. If the nodes are closely connected to each other, we can evaluate that they are likely to form a strong and cohesive group. Also, in network analysis, if a node $A$ is connected to another node $B$, and that node $B$ is connected to node $C$, we evaluate that $A$ and $C$ are connected even if they are not directly connected. This is because node A may obtain information from node $C$ via node $B$, and may be affected by it. However, in this case, the strength of the relationship between node $A$ and node $B$ may be different from the strength of the relationship between node $A$ and node $C$. Closeness centrality in network analysis methods evaluates the 
number of close relationships, rather than the simple number of connections, by giving greater weight to more direct connections. It can be said that network density and closeness centrality evaluate relationships as opposed to the weak ties, mediation, or structural holes mentioned above.

Also, these can be related to the integrated inter-organizational relationships among the previous studies on inter-organizational relationships mentioned above. According to various studies on organizational capabilities and organizational learning, open interorganizational networks and platforms may not necessarily promote companies' growth. As the change to automated vehicles progresses, it is assumed that many management resources will be required if a single company tries to tackle development of the aforementioned diverse issues as a whole. While the so-called ecosystem as a whole is advancing innovation, a scenario in which each company limits its role to part of the ecosystem and concentrates its development resources is also possible. In other words, the size and shape of individual companies' inter-organizational networks may remain the same even if the overall network structure changes as the shift to self-driving cars progresses.

In addition, according to previous studies on modularity traps, if the change to automated vehicles is in the early stage of a large technological life cycle, individual companies will integrate their product structures vertically, and inter-organizational networks' structures will become closed and dense. In the current situation, the dominant design is not necessarily clear yet amid the shift to automated vehicles, and various new technologies and business models are appearing successively. The industry as a whole remains in a chaotic state, and it is expected to take several decades for the dominant design to be established (Fujimoto, 2020). If the technology life cycle's early stage continues for a very long time, the industrial structure and inter-organizational network may not change abruptly. In fact, existing automakers actively are investing in new technological areas while maintaining and extending the life of profitable existing businesses and the cohesive interorganizational networks that support existing businesses as much as possible. They may collaborate with both new and old partners, and inter-organizational relationships may become more vertically integrated. From the above assumptions, the following hypothesis is proposed:

Hypothesis 3: The more dense an inter-organizational network is in the automated-vehicle industry, the more it grows.

Hypothesis 3: The more closed an inter-organizational network is in the automated-vehicle industry, the more it grows.,

\section{$4 \quad$ Research Methodology}

\subsection{Research Data}

Next, WE discuss the methodology used to verify each of the aforementioned research hypotheses empirically. As a data-collection source, this study used data from newspaper articles and corporate press releases, through which it is possible to collect comprehensive, integrated, and timely data on the relationships among many firms. For example, in the case of data on mergers and acquisitions, more accurate data can be collected by using investor relations materials, such as companies' annual reports. In the case of joint R\&D data, it also is possible to collect data from patent applications. However, this survey aimed to collect information on a wider range of relationships. For example, alliance relationships are included in the survey, as well as trade relationships involving parts and materials, because understanding such changes in the 
supply chain is also an important goal of this survey. In addition, to understand the so-called corporate ecosystem's overall structure, it is also important to understand the development of products and services by using other companies' open technologies. It is not always the case that a clear business relationship exists between the companies that comprise the ecosystem. For example, in the IT industry, the development of various applications and devices using the USB interface of PCs and Google's OS as a platform has allowed the entire ecosystem to expand and the industry as a whole to grow. Furthermore, the suppliers of various apps and devices do not necessarily have clear contractual relationships with Intel or Google. Jacobides (2019) cites the relationship between Apple and 2 million app developers for Apple's iPhone as an example of the relationships that comprise a business ecosystem. In this study, these very loose relationships between firms are also important in analyzing the firms' growth and were included in the survey.

The automobile industry, including its related industries, is a global industry, and each company operates beyond the boundaries of a specific country or region and has relationships with a variety of external companies. This also applies to automated vehicles, and it is assumed that various companies worldwide have established comprehensive relationships with each other. However, the current state of the automobile industry, its historical background, and each company's characteristics are not necessarily uniform among regions and nations, e.g., the U.S., China, Japan, and Europe. For example, the U.S. is ahead of other countries in IT-related technologies and is making new attempts at advances, such as public road tests of automated driving. In Japan and Europe, relatively conventional, vertically integrated automakers are driving technological development. In China, few existing legacies and many emerging companies exist. Product-design concepts and companies' competitive advantages differ among these nations and regions, and inter-organizational networks' structures also are expected to differ. Therefore, a more accurate analysis will be possible by examining them comprehensively and categorizing them as appropriate.

Newspaper articles and press releases are viewed as the only media through which to collect data on such diverse relationships in a comprehensive and global manner. Of course, one of the problems with newspaper article data is that they are biased due to story selection at the article stage, depending on individual companies' editorial policies. This survey searches through not only individual media companies' newspaper article data, but also various newspaper articles from all over the world that are digitized in English, to collect as comprehensive a collection of data as possible. Specifically, the Lexis Advance database, created by LexisNexis of the U.S., was used as the data source. The author's university has a contract with Lexis Advance, which allows for full-text searches and browsing of newspaper articles from the world's leading newspapers, including the New York Times, Los Angeles Times, Le Monde, and others.

As for the extraction conditions with the articles, the following keywords were used for the search, which correspond to self-driving cars: "autonomous car, self-driving car, autonomous vehicle, connected and autonomous vehicle, driverless car, robo-car, robotic car, automatic transport vehicle."

Articles that contained the above search terms and included more than one company were extracted. For the target period of extraction, the period for evaluating the growth of companies was set at five years, and articles from 2019 and 2015 were extracted. As extraction conditions, the language was English only, and the publication-type was limited to newswires and press releases only, excluding other data such as journal articles, theses, and blogs to avoid data duplication. 


\subsection{Analytical Method}

After constructing the database for the analysis as described above, the analysis of the database was conducted through the following steps to verify each hypothesis. First, prior to the analysis, the database for analysis was cleaned using text-mining methods. Next, the structure of each company's inter-organizational network was analyzed using the network-analysis method, and each company's degree of growth was evaluated. Finally, the relationship between the interorganizational network's structure and the degree of growth was analyzed. Each procedure's details are as follows.

\section{Data cleaning}

The database for the analysis was based on newspaper articles, and the notation of company names, product names, industry names, locations, and inter-firm relationships is not consistent. For example, some company names are complete, while others include abbreviations, common names, or notation errors. Therefore, all the words and compound words in the entire database were extracted using text-mining techniques, and the notations were unified or grouped. Company names were extracted, compared, and transformed to match perfectly, as they are key items in the analysis described below. For regions and inter-firm relationships, categorization was conducted based on the extracted words and phrases' semantic content. KH Coder (Version 3) was used for text mining, and categorization was done using coding rules, a $\mathrm{KH}$ Coder function (Higuchi, 2016, 2017).

The extracted relationships between companies were narrowed to the relationships that correspond to the business ecosystem, which is the target of this study's analysis. Considering that the relationships among firms in the extracted articles include competitive and litigation relationships, the relationships were limited to those corresponding to the following. Extracted relationships include, first, strong relationships based on capital relationships, such as acquisition, investment, funding, parent company, and subsidiary. Second, alliances and partnerships - such as partnership, alliance, joint venture, joint development, joint test, cooperative, and support also were extracted. In addition, mainly transactional relationships in the market - such as client, offer, supply, integration, commitment, and marketing - were extracted.

\section{Network analysis}

Next, each company's inter-organizational network structure was analyzed according to each hypothesis based on the database for analysis after data cleaning. For the inter-organizational network structure analysis, each company was viewed as a node in the network, and the social network analysis method was applied. Using social network analysis, various indicators that show the characteristics of the network's structure can be calculated (Borgatti, Everett, \& Freeman, 2002). In this study, the following network indices were used among them:

As for Hypothesis 1, degree centrality, which represents the size of the ego network comprising nodes connected to the company in question, was calculated as a network indicator of network size.

In Hypothesis 2, EgoBetweeness and constraint were calculated as network indicators for platform companies. EgoBetweeness is an index that indicates that the firm in question connects other firms that are not directly connected to each other. Network size affects this index, e.g., if the ego network's size increases, the number of intermediaries may increase naturally, so nEgoBetweeness, which is an index showing the normalized ratio, was used. 
Constraint indicates the denseness of the network surrounding the firm in question. If this index's value is small, the network around the firm is sparse, indicating that the firm plays the role of a bridge in the ego network. Therefore, the size of a structural hole is evaluated using the inverse of the degree of constraint.

Eigenvector centrality also was calculated as an indicator of the size of the connection to nodes with large mediation centrality. Eigenvector centrality is not a simple centrality, but one that is loaded based on collaborations with highly centric firms.

As for Hypothesis 3, ego network density and closeness centrality were calculated as indicators of interorganizational networks' cohesiveness and closeness. The ego network's density is the degree of connection between each node in the ego network, and the higher the density value, the more closely connected the nodes are. It is estimated that the value will increase as the grouping of companies progresses. Closeness centrality is a centrality that is loaded based on the relationship between nodes that are close in distance and is factored in to indicate the number of companies with close relationships. UCINet (Version 6) was used to calculate network indices.

\section{Analysis of the degree of growth}

Next, an evaluation index for each firm's degree of growth was calculated. As a proxy variable for the evaluation index, the difference in the size of the ego network from 2015 to 2019 was employed for each firm. A company's growth index can be sales, profit margin, or corporate value, but in this study, it is desirable to evaluate the degree of growth of businesses related to automated vehicles. However, it is difficult to extract sales and profits related to automated vehicles separately from financial statements, etc., because automakers and other companies are engaged in businesses related to conventional automobiles and various other businesses.

In addition, although corporate value is supposed to be the sum of future profits, it is difficult to use it as an index in such a novel business field because market evaluation is difficult to determine, and market environment and investors' speculation easily influence it. Therefore, in this study, it was decided that the evaluation would be based on data extracted from information on automated vehicles. As mentioned earlier, in the area of automated vehicles, the degree to which the ecosystem surrounding a company is expanded significantly impacts the company's growth potential and is assumed to be an important strategic goal of each company. Therefore, the ecosystem's growth was viewed as a proxy variable for the degree of growth for firms in this study.

A correlation analysis between each firm's network index and growth was conducted to test the hypothesis. SPSS (Version 25) was used for the correlation analysis.

\section{Survey Results}

\subsection{Overview of the Survey}

As an overview of the conducted survey based on the aforementioned survey method, the number of articles extracted was 4,240 in 2015 and 7,315 in 2019, and the number of companies extracted was 2,278 , with 44,618 combinations among these companies. The firms included nonprofit organizations, such as universities and public research institutions. The above number of companies indicates that not only automobile and automobile parts manufacturers, but also a large number of various companies are engaged in some kind of activities related to automated vehicles. Out of 44,618 combinations of companies, data corresponding to relationships 
encompassed by business ecosystems were selected as described above, resulting in 4,634 in 2015 and 15,429 in 2019, for a total of 20,063. These were the original data analyzed.

To compare differences among regions, the analysis was divided into articles on the U.S., China, Europe, and Japan. In this regional classification, overlap is allowed. For example, if an article's content was related to both the U.S. and Japanese markets, it was included in the analysis for the U.S. and Japan because the scope of activities and cooperation among automobile-related companies is international, making it difficult to separate them. As a result, total firms and combinations of firms analyzed by each region were 891 firms and 12,129 pairs in the U.S., 317 firms and 3,164 pairs in China, 201 firms and 2,691 pairs in Japan, and 612 firms and 8,280 pairs in Europe. The U.S. classification includes the Americas, encompassing Canada and South America. These are viewed as having significant industrial and market connections with the U.S. Europe includes not only Western Europe, but also Central and Eastern Europe. However, there are articles on other regions, such as Asian countries other than Japan and China, and the Middle East, but these regions were not included in the analysis because almost no major automakers and few related articles exist from these regions.

\subsection{Results From Correlation Analysis}

Table 1 shows the results from the correlation analysis between each company's network structure and its growth potential, calculated using the aforementioned procedure.

Table 1: Correlation Coefficients between Network Indicators and Growth Potential

\begin{tabular}{|c|c|c|c|c|}
\hline & U.S. & China & Japan & Europe \\
\hline Degree Centrality & $.96^{* *}$ & $.98^{* *}$ & $.99^{\star *}$ & $.93^{* *}$ \\
\hline nEgoBetweeness & $.13^{* *}$ & -0.00 & 0.06 & $.13^{* *}$ \\
\hline Constraint & $-.62^{* *}$ & $-.71^{* *}$ & $-.72^{* *}$ & $-.61^{* *}$ \\
\hline Eigenvector centrality & $.73^{\star \star}$ & $.86^{\star \star}$ & $.86^{\star \star}$ & $.64^{\star \star}$ \\
\hline Density & $-.41^{* *}$ & $-.26^{\star *}$ & $-.40^{\star *}$ & $-.43^{\star *}$ \\
\hline Closeness centrality & $-.38^{\star \star}$ & $-.43^{\star \star}$ & $-.48^{\star \star}$ & $-.38^{\star \star}$ \\
\hline
\end{tabular}

\section{Discussion}

Based on the aforementioned survey results, each hypothesis was verified. The first hypothesis concerned network size, i.e., the larger the network, the faster the growth rate. A significant correlation was found between the two indicators, regardless of the region of analysis, indicating that the hypothesis may be supported. Technology related to automated driving and its market remains in the growth process, and it can be inferred that no dominant technology exists yet, with various attempts being made. Rather than focus on strong collaboration among specific firms, each firm may gather a wide range of technical information and promote innovation by collaborating with many firms. In addition, by expanding collaboration among firms, the 
standardization of their own technologies and business models is promoted, and such firms also may have the power to attract various firms to collaborate with them.

It can be inferred that the number of collaborators is related closely to the company's size, and that large companies with the capacity to invest in research and development of new technologies are growing. In fact, existing automakers are merging aggressively with other large companies to expand their scale and forge new inter-organizational relationships related to new businesses while preserving inter-organizational relationships in existing businesses with high profitability. The results from this analysis are consistent with actual trends.

The second hypothesis is the mediation hypothesis, i.e., companies that form inter-organizational relationships with greater mediation or structural holes experience more growth. Regarding this hypothesis, differences among regions were confirmed depending on the indicators measured. The index of mediation is not simply an indicator of a large number of associations, as in the case of degree centrality described above, but an indicator that a particular node is the only route in the connection between many other firms. nEgoBetweeness is a measure of the extent to which a firm is the only connection route to other firms. In other words, nEgoBetweeness is an indicator of the extent to which other firms are not directly connected to each other. As an index of mediation, it can be said that it is a strong index of mediation with strict conditions.

The results from the analysis showed that a significant positive correlation exists between nEgoBetweenness, a strong index of mediation, and growth potential in the U.S. and Europe. However, no significant correlation was found in Japan and China. The results from this analysis indicate that there may be strong platform companies in the U.S. and Europe in the industry domain of automated vehicles, and that platform companies may not be growing in Japan and China. While searching for individual company cases in the database for analysis, Waymo, Uber, Nvidia Corporation, and Intel Corporation were extracted as the companies with the highest $\mathrm{nEgoBetweeness} \mathrm{values.} \mathrm{Waymo} \mathrm{is} \mathrm{a} \mathrm{self-driving-car-related} \mathrm{development} \mathrm{company} \mathrm{under} \mathrm{the}$ umbrella of Alphabet, Inc., which includes Google LLC. Waymo is the leader in self-driving technology with an overwhelming track record, along with China's Baidu, Inc., in terms of the number of self-driving cars tested on public roads. Although Uber sold its self-driving division to Aurora, another U.S. self-driving technology company, at the end of 2020 due to the deteriorating performance of its core business, it invested heavily in $R \& D$ until then. Nvidia is a leader in the development of components for automated driving, with an emphasis on image-processing technology, which is one of the core technologies for automated driving. Intel also acquired Mobileye, an Israeli company that is a world leader in the same technology as Nvidia, and has become a leader in core components for automated driving. These companies have very high potential to become so-called platform leaders in the automated vehicle industry in the future. In Europe, Continental AG and Denso Corporation, which are automotive parts manufacturers, registered the highest $\mathrm{nEgoBetweeness}$ values during the search. All these companies are potential platform leaders in automated driving.

However, the results from the search of the database for analysis in Japan and China found no companies with a position that corresponded with the aforementioned clear platform leader, and that existing companies and new entrants, both large and small, were working on their own growth. In the case of Japan, the presence of existing large automobile manufacturers is particularly significant, and powerful venture-type companies have not grown necessarily. In the case of China, although the aforementioned Baidu is ahead of the competition, countless 
companies have entered the market, and Western automakers also are competing for dominance in the Chinese market. It is difficult to say which one will become the platform leader.

Constraint was correlated significantly with growth potential regardless of region. The inverse of constraint is an indicator of the degree of structural holes. Inverse of constraint is a measure of the degree of structural voids, e.g., the degree to which a node connects multiple clusters. This is a slightly weaker mediating indicator than $\mathrm{nEgoBetweenness,} \mathrm{in} \mathrm{the} \mathrm{sense} \mathrm{that} \mathrm{the} \mathrm{firms} \mathrm{in} \mathrm{each}$ cluster may be connected. In particular, in industries such as automated driving, in which several new technologies are being created successively, collection of such information leads to the creation of knowledge and promotes growth, which is consistent with previous studies.

Eigenvector centrality is also correlated significantly with growth, regardless of region. Eigenvector centrality indicates the degree to which a firm is connected to a highly centralized firm, such as degree centrality, which is assumed to include, for example, a niche firm that possesses some rare technology. In the self-driving car industry, which is a new and risky technological domain, collaborations with giant companies that are investing actively in the industry are likely to increase the likelihood of growth together. Furthermore, if the self-driving car industry is like the IT industry, in which network externalities are strong - based on some technological standards, customer base, etc. - then ties with core companies will be even more important for growth.

The third hypothesis concerned network density and closeness, and it opposes the other two hypotheses. For this hypothesis, a significant negative correlation was observed regardless of the region of analysis, indicating that the alternative hypothesis may be rejected. As mentioned earlier, in the existing automobile industry, cohesiveness is one of the characteristics of interorganizational relationships, and by forming highly cohesive corporate groups, growth and profitability were enhanced. However, in the new industrial domain of automated vehicles, the lower the cohesion, the higher the growth, i.e., inter-organizational relationships' characteristics are the exact opposite of those in the past.

One possible reason for this analysis is that self-driving cars remain in their infancy in the technological life cycle, and that the technology and industry remain immature and exploratory, with no organized development or production among companies. In previous studies, cohesive and strong networks were found to be useful during the stage of full-scale commercialization of technology. However, it is also likely that the technology's life cycle has passed the dawn stage and entered the growth stage because the analysis so far suggests that certain highly centralized companies already are accelerating their growth, and that platform leaders are being formed in technologically advanced regions, such as the U.S. If they are in the growth phase, it is highly likely that a decentralized, horizontal, division-of-labor-type industrial structure with a platform leader at its core will become mainstream in the automated driving industry, similar to the IT industry, as the results from the previous analysis have shown.

If this estimation is correct, it may force existing automakers to change their business structures significantly. Japanese automakers in particular are likely to lose their main source of competitive advantage, which traditionally has been pointed out to be management of inter-organizational relationships. In other industries, similar changes have occurred, starting with the decline of companies with vertically integrated organizational structures in the computer industry in the 1980 s and 1990s, and continuing in various other industries, including the consumer electronics industry. In the face of such changes in industry structure, companies characterized by vertically integrated inter-organizational relationships have lost their competitive advantage successively. 
However, companies that have forged platform-type inter-organizational relationships have succeeded in growth. This study's results indicate that a similar change already may be underway in the automotive industry with the emergence of the new technological domain of automated driving.

\section{Conclusion}

This study's purpose was to examine empirically the effect from interorganizational relationships surrounding a company on its growth potential. Particularly in the automotive industry, the advantage of cohesive and vertically integrated inter-organizational relationships has been pointed out conventionally. This study aimed to examine whether rapid changes in the technological environment affect inter-organizational relationships.

The results from an analysis of a large number of databases indicated that the technological change from automated driving, which would change the entire industry's structure, may have prompted a change in inter-organizational relations toward a horizontal division of labor in the automobile industry in which so-called platform leader companies would emerge. This study's significance is that it is empirical and based on a large amount of data on actual corporate activities. The self-driving car, which was the subject of analysis in this study, is a field that currently is attracting a great deal of attention, both in industry and academia, with discussions and other information being published online and in various other media, as well as in academic papers. However, the discourse sometimes focuses only on some particular cases or specific technologies, the perspectives and arguments are diverse, and the conclusions are not always the same. The fact that this study exploratively tried to analyze the current situation as a new, unevaluated subject based on the analysis of a large amount of actual data, as well as attempted to provide evidence concerning the characteristics of growing companies' interorganizational networks, is viewed as an implication for research and practice.

However, as a future issue, the industrial structure in this area remains in flux and is expected to change in the future, so the results from this analysis cannot be used as a fixed conclusion. In addition, it cannot be denied that the analysis, based on newspaper article data, may differ from reality, so it is necessary to conduct a continuous analysis while supplementing it with other methods.

\section{References}

BORGATTI, S. P., EVERETT, M. G., and FREEMAN, L. C. (2002) Ucinet for Windows: Software for Social Network Analysis. Boston, MA: Analytic Technologies.

BURT, R. (1992) Structural holes: The Social Structure of Competition. Cambridge, MA: Harvard University Press.

BURT, R. (2004) Structural Holes and Good Ideas. American Journal of Sociology. Vol. 110, No. 2, pp. 349-399. https://doi.org/10.1086/421787

CECCAGNOLI, M., FORMAN, C., HUANG, P., and WU, D. J. (2012) Cocreation Of Value in a Platform Ecosystem: The Case of Enterprise Software. MIS Quarterly. Vol. 36, No. 1, pp. 263-290. https://doi.org/10.2307/41410417

CENNAMO, C., and SANTALO, J. (2013) Platform Competition: Strategic Trade - Offs in Platform Markets. Strategic Management Journal. Vol. 34, No. 11, pp.1331-1350. https://doi.org/10.1002/smj.2066 
CHESBROUGH, H. (2003) The Logic of Open Innovation: Managing Intellectual Property. California Management Review. Vol. 45, No. 3, pp. 33-58. https://doi.org/10.1177/000812560304500301

CHESBROUGH, H., and KUSUNOKI, K. (2001) The Modularity Trap: Innovation, Technology Phase Shifts, and the Resulting Limits of Virtual Organizations. Managing Industrial Knowledge. pp. 202-230. https://doi.org/10.4135/9781446217573.n11

COHEN, W. M., and LEVINTHAL, D. A. (1990) Absorptive Capacity: A New Perspective on Learning and Innovation. Administrative Science Quarterly. Vol. 35, No. 1, pp.128-152. https://doi.org/10.2307/2393553

FUJIMOTO, T. (2020) Critiquing the Recent Discussions on Manufacturing with Questionable Evidence. Akamon Management Review. Vol. 19, No. 5, pp.159-164.

GAWER, A., and CUSUMANO, M. A. (2002) Platform Leadership: How Intel, Microsoft, and Cisco Drive Industry Innovation. Boston, MA: Harvard Business School Press.

GAWER, A., and CUSUMANO, M. A. (2008) How Companies Become Platform Leaders. MIT Sloan Management Review. Vol. 49, No. 2, pp. 28-35.

GAWER, A., and CUSUMANO, M. A. (2014) Industry Platforms and Ecosystem Innovation. Journal of Product Innovation Management. Vol. 31, No. 3, pp. 417-433. https://doi.org/10.1111/jpim.12105

GRANOVETTER, M. S. (1973) The Strength of Weak Ties. American Journal of Sociology. Vol. 78, No. 6 , pp. 1360-1380. https://doi.org/10.1086/225469

GRANOVETTER, M. S. (2005) The Impact of Social Structure on Economic Outcomes. Journal of economic perspectives. Vol. 19, No. 1, pp. 33-50. https://doi.org/10.1257/0895330053147958

HIGUCHI, K. (2016) A Two-Step Approach to Quantitative Content Analysis: KH Coder Tutorial Using Anne of Green Gables (Part I). Ritsumeikan Social Science Review. Vol. 52, No. 3, pp. 77-91. PDF file.

HIGUCHI, K. (2017) A Two-Step Approach to Quantitative Content Analysis: KH Coder Tutorial Using Anne of Green Gables (Part II). Ritsumeikan Social Science Review. Vol. 53, No. 1, pp. 137-147. PDF File.

IANSITI, M., and LEVIEN, R. (2004) The Keystone Advantage: What the New Dynamics of Business Ecosystems Mean for Strategy, Innovation, And Sustainability. Boston, MA: Harvard Business Press.

JACOBIDES, M. G. (2019) In the Ecosystem Economy, What's Your Strategy? Harvard Business Review. Vol. 97, No. 5, pp. 128-137.

LANE, P. J., and LUBATKIN, M. (1998) Relative Absorptive Capacity and Interorganizational Learning. Strategic Management Journal, Vol. 19, No. 5, pp. 461-477. https://doi.org/10.1002/(SICl)10970266(199805)19:5<461::AID-SMJ953>3.0.CO;2-L

MARCH, J. G. (1991) Exploration and Exploitation in Organizational Learning. Organization Science. Vol. 2, No. 1, pp. 71-87. https://doi.org/10.1287/orsc.2.1.71

MURASAWA, Y. (2010) Electric Vehicles: A Major Shift to A Non-Burning Civilization. Tokyo, Japan: Chikuma Shobo.

SAEKI, Y. (2011) Technical Characteristics and Auto-Parts Transactional Relationship of Electric Vehicle Market from The Perspective of Architecture-Based Analysis. Ritsumeikan Business Journal. Vol. 5, pp. 25-49.

TEECE, D. J., PISANO, G., and SHUEN, A. (1997) Dynamic Capabilities and Strategic Management. Strategic Management Journal. Vol. 18, No. 7, pp. 509-533. https://doi.org/10.1002/(SICl)10970266(199708)18:7<509::AID-SMJ882>3.0.CO;2-Z 
ULRICH, K. (1995) The Role of Product Architecture in The Manufacturing Firm. Research Policy, Vol. 24, No. 3, pp. 419-440. https://doi.org/10.1016/0048-7333(94)00775-3

WESSEL, M., LEVIE, A., and SIEGEL, R. (2016) The problem with legacy ecosystems. Harvard Business Review. Vol. 94, No. 11, pp. 68-74. 